\title{
Impact of Histone Deacetylase Inhibitors SAHA and MS-275 on DNA Repair Pathways in Human Mesenchymal Stem Cells
}

\author{
GIOVANNI DI BERNARDO,' NICOLA ALESSIO, ${ }^{2,4}$ CARMELA DELL'AVERSANA,,6 \\ FIORINA CASALE, ${ }^{5}$ DIANA TETI, ${ }^{6}$ MARILENA CIPOLLARO,' LUCIA ALTUCCI, \\ AND UMBERTO GALDERISI ${ }^{1,2 *}$
}

'Department of Experimental Medicine, Section of Biotechnology and Molecular Biology "A Cascino", Second University of Naples, Naples, Italy

${ }^{2}$ Sbarro Institute for Cancer Research and Molecular Medicine, Center for Biotechnology, Temple University, Philadelphia, Pennsylvania

${ }^{3}$ Department of general Pathology, Second University of Naples, Naples, Italy

${ }^{4}$ Department of Biomedical Sciences, Division of Biochemistry and Biophysics, University of Sassari, Sassari, Italy

${ }^{5}$ Department of Pediatrics "F. Fede", Second University of Naples, Naples, Italy

${ }^{6}$ Dipartment of Pathology and Experimental Microbiology University of Messina, Messina, Italy

${ }^{7}$ CNR-IBG, Stem Cell Fate Lab., Naples, Italy

\begin{abstract}
Histone deacetylase inhibitors (HDACis) have received considerable attention for their anti-tumoral properties. We report here the effects of two HDACis, SAHA and MS-275, on the biology of mesenchymal stem cells (MSCs). It is well known that HDACis trigger both DNA damage responses and actual DNA damage in cancer cells. On this premise, we evaluated HDACis influence on DNA damage pathways in MSCs. We analyzed a panel of genes involved in the regulation of base and nucleotide excision repair, mismatch repair, and double strand break repair. That a majority of the analyzed genes displayed significant expression changes upon incubation with SAHA or MS-275 suggested that regulation of their expression is greatly affected by HDACis. The complex expression pattern, with some genes up-regulated and other under-expressed, did not allow to foresee whether these changes allow cells cope with stressful DNA damaging stimuli. Furthermore, we evaluated the biological outcome following treatment of MSCs with DNA damaging agents $\left(\mathrm{H}_{2} \mathrm{O}_{2}\right.$ and $\left.U V\right)$ in presence of HDACis. In these settings, MSCs treated with $\mathrm{H}_{2} \mathrm{O}_{2}$ or UV radiation underwent apoptosis and/or senescence, and pre-incubation with HDACi exacerbated cell death phenomena. Accordingly, the number of cells harboring 8-oxo-7,8-dihydroguanine (8oxodG), a hallmark of DNA oxidative damage, was significantly higher in samples incubated with HDACis compared to controls. In summary, our findings suggest that SAHA and MS-275, even at low effective doses, can alter the biology of MSCs, diminishing their ability to survive the effects of DNA-damaging agents.
\end{abstract}

J. Cell. Physiol. 225: 537-544, 2010. (C) 2010 Wiley-Liss, Inc.

Bone marrow of mammals comprises several different components that support both hematopoiesis and bone homeostasis. Among these are mesenchymal stem cells (MSCs), non-hematopoietic stem cells possessing multilineage potential (Muller-Sieburg and Deryugina, 1995; Zhang et al., 2003).

Aside from differentiation in mesenchymal tissues, MSCs support hematopoiesis and contribute to the homeostatic maintenance of many organs and tissues (Prockop, 1997; Beyer Nardi and da Silva Meirelles, 2006; Sethe et al., 2006), thus justifying that impairment of MSC functions may have profound consequences on body physiology. Anticancer drugs often alter functions of the bone marrow microenvironment and hence affect MSCs.

In the past several years, histone deacetylase inhibitors (HDACis) have received considerable attention for their antitumoral properties both in vivo and in vitro. Their anti-cancer properties result from reversal of gene silencing, induction of cell cycle arrest, differentiation, and/or apoptosis (Dokmanovic and Marks, 2005; Rodriquez et al., 2006).

HDACis act on chromatin remodeling, a key mechanism of gene expression regulation. During activation of gene

All authors have no financial and personal relationships with other people or organizations that could inappropriately influence (bias) their work.

Additional Supporting Information may be found in the online version of this article.

Contract grant sponsor: Sbarro Health Research Organization. Contract grant sponsor: EU-FP7 ATLAS Project;

Contract grant number: 221952 .

Contract grant sponsor: Associazione Italiana per la Ricerca sul Cancro.

*Correspondence to: Umberto Galderisi, Department of Experimental Medicine, Section of Biotechnology and Molecular Biology, Second University of Naples, Via Costantinopoli 16, 80138 Napoli, Italy. E-mail: umberto.galderisi@unina2.it

Received 25 March 2010; Accepted 29 April 2010

Published online in Wiley Online Library (wileyonlinelibrary.com.), 10 May 2010. DOI: $10.1002 /$ jcp.22236 
expression, tight chromatin structure is released by nucleosome modifications, thus enabling the binding of transcription factors to gene promoters. On the other hand, chromatin compaction represses gene expression. The chromatin remodeling process can be modulated by post-translational histone modifications. The most frequently studied histone modification is acetylation, which is primarily associated with activation of gene expression, whereas histone deacetylation is related to transcriptional repression. Steadystate levels of histone acetylation result from a balance between opposing activities of histone acetyltransferases (HATs) and histone deacetylases (HDACs) (Santos-Rosa and Caldas, 2005).

Defects in the status of histone acetylation have been described for several types of cancer in which HDACs are inappropriately expressed or recruited to several gene promoters. These findings have prompted an extensive search for drugs capable of modulating HDAC activity, such as HDAC inhibitors (Santos-Rosa and Caldas, 2005).

HDACis can be divided into several chemical classes, including hydroxamates, cyclic peptides, short fatty acids and benzamides. Suberoylanilide hydroxamic acid (SAHA) and MS275 belong to the first and last class of HDACis, respectively (Heltweg et al., 2004; Dokmanovic and Marks, 2005). These are among the most promising compounds for cancer treatment; SAHA is a pan-inhibitor, and MS-275 is a class I selective inhibitor. SAHA is under investigation in several clinical trials. Preliminary results have demonstrated that SAHA is effective against several hematological and solid malignancies. In particular, Vorinostat ${ }^{\mathbb{R}}$ (also named Zolinza) is the first HDACi-based drug approved from the FDA for the treatment of CTCL (cutaneous T-cell lymphoma) (Duvic and Vu, 2007; Duvic et al., 2007). MS-275 is also under analysis for the treatment of some tumors (Kummar et al., 2007; Ramalingam et al., 2007) with the name of Entinostat.

Despite their use in the clinic, the mechanism(s) of action of HDACis are not fully understood. Indeed, normal cells are relatively resistant to the cytotoxic effects observed in tumor cells that are exposed to HDACis. Several hypotheses have been proposed for the basis of this selective toxicity, but a distinct mechanism has yet to be elucidated (Dokmanovic and Marks, 2005; Ungerstedt et al., 2005). Therefore, a better understanding of the biological effects of these compounds is essential for the successful development of new anticancer agents with minimal side effects in order to avoid impairment of the bone marrow microenvironment, including MSCs.

Among the several mechanisms of action, HDACis trigger both DNA damage responses and actual DNA damage in cancer cells. On this premise, we evaluated their influence on DNA damage pathways in MSCs. Our preliminary data (Di Bernardo et al., 2009), showed that both SAHA and MS-275 induced cell cycle arrest and apoptosis. MS-275 treatment resulted in an increase in the number of senescent cells, whereas cells treated with SAHA were less likely to enter senescence when compared with control cells.

In the current study, we analyzed the action of HDACis on MSCs. DNA damage is a powerful inducer of programmed cell death and/or senescence. Considering that apoptosis and senescence are the main outcomes following stress stimuli that impair cellular function, we investigated if DNA damage pathways play a role in biological effects of HDACis in MSCs.

\section{Materials and Methods} MSC cultures

Bone marrow was obtained from healthy donors after informed consent. We separated cells on the Ficoll density gradient (GE Healthcare, Milano, Italy), and the mononuclear cell fraction was collected and washed in PBS. We seeded I-2.5 $\times 105 \mathrm{cells} / \mathrm{cm}^{2}$ in $\alpha$-MEM containing $10 \%$ FBS and $2 \mathrm{ng} / \mathrm{ml}$ bFGF. After $72 \mathrm{~h}$, nonadherent cells were discarded, and adherent cells were further cultivated to carry out experiments.

We verified that under our experimental conditions, MSC cultures fulfilled the three proposed criteria to define MSCs:

(i) adherence to plastic, (ii) specific surface antigen expression, and (iii) multipotent differentiation potential. First, MSCs were selected by the plastic-adherence procedure. More than $90 \%$ of the MSC population expressed the CDI05, CD73, and CD90 antigens as detected by immunocytochemistry experiments (data not shown). Additionally, we verified that the MSCs were able to differentiate into osteoblasts, adipocytes, and chondroblasts (Dominici et al., 2006).

All cell culture reagents were obtained from Euroclone Life Sciences (Milano, Italy) and Hyclone (Logan, UT) unless otherwise stated.

HDACi treatment. Cells were incubated for $72 \mathrm{~h}$ with I $\mu \mathrm{M}$ SAHA or I $\mu$ M MS-275 and then collected for analysis.

\section{Treatment with DNA-damaging agents}

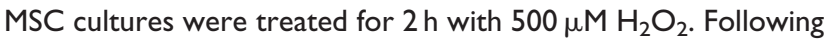
treatment, the medium was removed, and complete medium preheated to $37^{\circ} \mathrm{C}$ was added.

For UV irradiation, cell plates with lids removed were irradiated with UV light by exposure to a germicidal lamp (peak sensitivity approximately $254 \mathrm{~nm}$ ) in a tissue culture hood $\left(15 \mathrm{~mJ} / \mathrm{cm}^{2}\right)$. Following treatment, the medium was removed, and complete medium preheated to $37^{\circ} \mathrm{C}$ was added.

TABLE I. RT-PCR analysis of DNA repair pathways

\begin{tabular}{|c|c|c|c|c|}
\hline DNA repair pathway & Gene & Primer position & PCR product length (bp) & Gene function \\
\hline \multirow[t]{3}{*}{ Double strand break (DSB) } & $\mathrm{BRCA} 2$ & 3732,3884 & 153 & DNA and protein binding \\
\hline & MREIIA & 675,775 & 101 & Endonuclease, exonuclease, hydrolase activity \\
\hline & $\mathrm{XRCC} 4$ & 781,881 & 101 & DNA and protein binding \\
\hline \multirow[t]{6}{*}{ Mismatch repair (MMR) } & MLHI & 1517,1634 & 117 & Match maker that coordinates multiple steps in MMR \\
\hline & TREXI & 1195,1305 & III & Exonuclease \\
\hline & $\mathrm{MSH} 2$ & 2058,2160 & 103 & Binds mismatch \\
\hline & MSH5 & 2353,2454 & 102 & Binds mismatch \\
\hline & PRKDC & 3141,3242 & 102 & Protein kinase as a molecular sensor for DNA damage \\
\hline & POLD3 & 178,305 & 128 & Protein binding \\
\hline \multirow[t]{6}{*}{ Base excision repair (BER) } & MUTYH & $1601,170 \mid$ & 101 & DNA glycosylase \\
\hline & MPG & 341,479 & 139 & DNA glycosylase \\
\hline & NTHL I & 331,443 & 113 & AP endonuclease activity and DNA glycosylase \\
\hline & FENI & 464,590 & 127 & Endonuclease activity \\
\hline & OGGI & 2074,2180 & 107 & DNA glycosylase \\
\hline & MBD4 & 384,487 & 104 & DNA glycosylase \\
\hline \multirow[t]{4}{*}{ Nucleotide excision repair (NER) } & XPA & 738,873 & 136 & A zinc finger protein involved in DNA excision repair \\
\hline & RAD23A & 146,255 & 110 & DNA and protein binding \\
\hline & ERCC3 & 1222,1324 & 103 & ATP-dependent DNA helicase \\
\hline & SLK & 2607,2713 & 107 & Nuclease activity \\
\hline
\end{tabular}




\section{Detection of apoptotic cells}

Apoptotic cells were detected with fluorescein-conjugated Annexin V (Roche, Monza, Italy) according to the manufacturer's instructions. Apoptotic cells were observed through a fluorescence microscope (Leica Microsystems Italia, Milano, Italy). In every experiment, at least I,000 cells were counted across different fields to calculate the percentage of dead cells in a culture.

Senescence-associated $\beta$-galactosidase assay

Cells were fixed for $10 \mathrm{~min}$ with a solution of $2 \%(\mathrm{v} / \mathrm{v})$ formaldehyde and $0.2 \%$ (w/v) glutaraldehyde. Fixed cells were washed with PBS and then incubated at $37^{\circ} \mathrm{C}$ for at least $2 \mathrm{~h}$ with a staining solution ( $30 \mathrm{mM}$ citric acid/phosphate buffer $(\mathrm{pH} 6)$, $5 \mathrm{mMK}_{4} \mathrm{Fe}(\mathrm{CN})_{6}, 5 \mathrm{mMK}_{3} \mathrm{Fe}(\mathrm{CN})_{6}, 150 \mathrm{mM} \mathrm{NaCl}, 2 \mathrm{mM} \mathrm{MgCl}$ and I $\mathrm{mg} / \mathrm{ml}$ X-Gal solution). The percentage of senescent cells was calculated by dividing the number of blue cells ( $\beta$-galactosidasepositive cells) observed across multiple fields by the total number of cells in those fields; at least 500 cells across different microscope fields were examined.

\section{RNA extraction, $\mathbf{R T}$, and real-time PCR}

Total RNA was extracted from cell cultures using TRI REAGENT (Molecular Research Center, Inc., Cincinnati, $\mathrm{OH}$ ) according to the manufacturer's protocol. The mRNA levels of the genes analyzed were quantified by real-time RT-PCR amplification, as previously reported (Galderisi et al., 1999).

Sequences of mRNAs from the nucleotide data bank (National Center for Biotechnology Information, USA) were used to design primer pairs for real-time RT-PCR reactions (Primer Express, Applied Biosystems, Foster City, CA). Primer sequences are available upon request. Appropriate regions of HPRT and/or GAPDH cDNA were used as controls. The real-time PCR assays were run on an Opticon 4 machine (MJ Research, Waltham, MA). Reactions were carried out according to the manufacturer's instructions using SYBR green PCR master mix. Amplifications were carried out using the following conditions: $95^{\circ} \mathrm{C}$ for $10 \mathrm{~min}$ (initial denaturation); then 40 cycles at $94^{\circ} \mathrm{C}$ for $10 \mathrm{sec}$

(denaturation), $59-6 \mathrm{I}^{\circ} \mathrm{C}$ for $20 \mathrm{sec}$ (annealing), and $72^{\circ} \mathrm{C}$ for $20 \mathrm{sec}$ (extension).

\section{Western blotting}

Cells were lysed in a buffer containing $0.1 \%$ Triton X-100 for $30 \mathrm{~min}$ at $4{ }^{\circ} \mathrm{C}$. Lysates were centrifuged for $10 \mathrm{~min}$ at $10,000 \mathrm{~g}$ at $4^{\circ} \mathrm{C}$. After centrifugation, 10-40 $\mu \mathrm{g}$ of each sample was loaded, resolved by electrophoresis on a polyacrylamide gel, and electroblotted onto a nitrocellulose membrane. Primary antibodies were used according to the manufacturers' instructions. Anti-PI07, PI6, P53, Cyclin E, Cyclin A, Cyclin DI, and alpha-tubulin were from Santa Cruz Biotech (Santa Cruz, CA). The first two antibodies were diluted $\mathrm{I}: 200$ and I:300, respectively. The others were diluted I:500. AntiRB and anti-P27 were from Cell Signaling (Danvers, MA) and were diluted $I: 2,000$ and $I: I, 000$, respectively. Anti-RB2 and anti-P2I were from BD Bioscience (Milano, Italy) and were diluted I:500. Anti-acetylated lys 382 P53 is from Millipore (Vimodrone (MI), Italy) and was diluted I:500.

Immunoreactive signals were detected with a horseradish peroxidase-conjugated secondary antibody (Santa Cruz Biotech) and reacted with ECL plus reagent (GE Healthcare).

The intensity of staining of each band was acquired with a CCD camera and analyzed with Quantity One I-D analysis software (Biorad Laboratories, Hercules, CA).

\section{8-Oxoguanine detection}

We detected 8oxodG within DNA by immunocytochemistry with an anti-8oxodG (clone 2E2) primary antibody (Trevigen, Gaithersburg, MD). Cells were stained with Hoechst 33342 and examined under a fluorescence microscope (Leica Microsystems

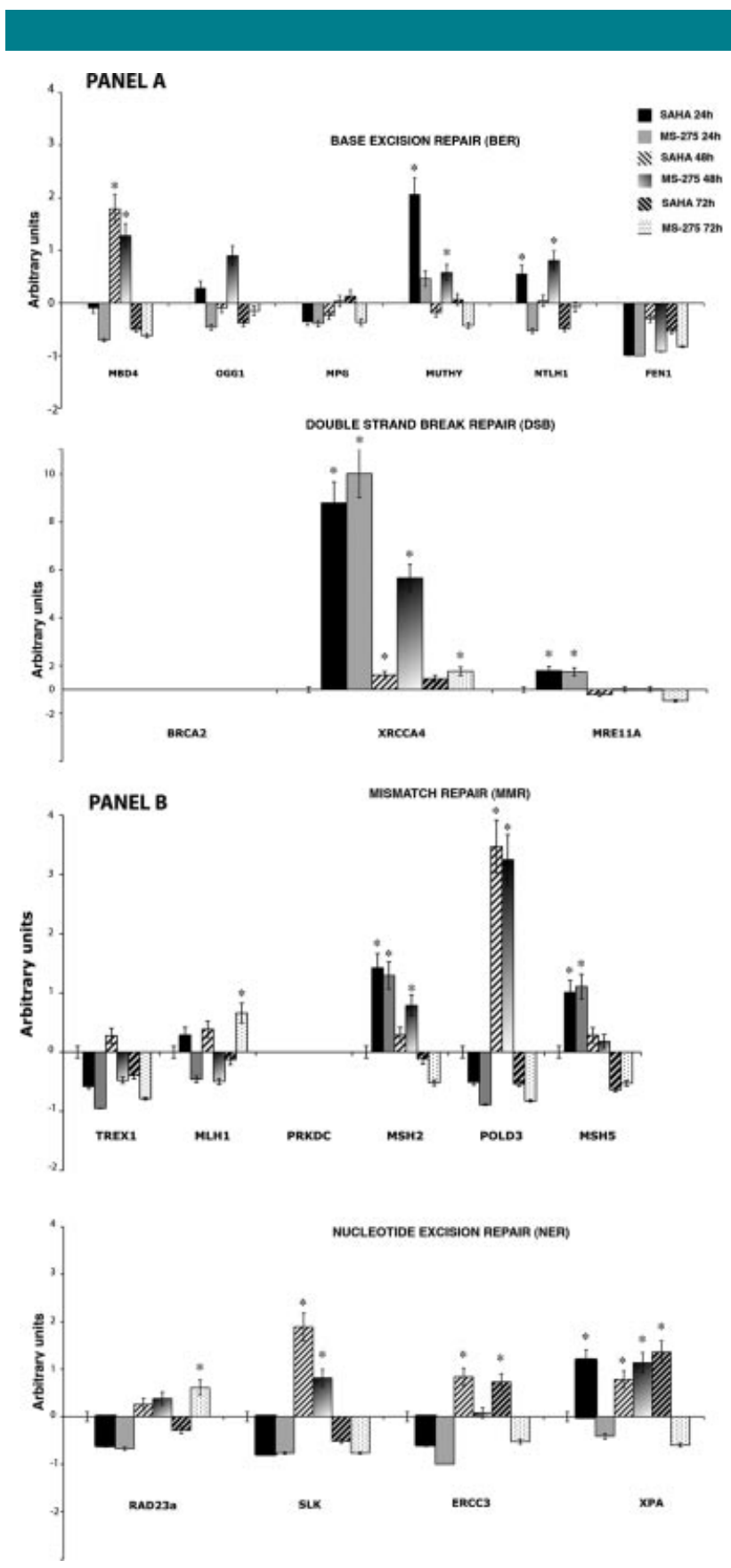

Fig. I. Quantitative RT-PCR analysis of mRNA expression from MSCs incubated with SAHA and MS-275 as compared with untreated cells (control cultures). The mRNA levels were normalized with respect to GAPDH, which was selected as an internal control. Each experiment was repeated at least three times. Histograms show mRNA expression levels at 24,48 , and $72 \mathrm{~h}$ post-treatment. They are expressed as arbitrary units with standard error. The expression level of each gene in control cultures is set as baseline (zero value). Expression levels in treated samples are shown as columns above (gene upregulation) or below (gene downregulation) the baseline of controls $\left({ }^{*} P<0.05\right)$. Part A: $m$ RNA levels of base excision repair (BER) and double strand break repair genes (DSB). BRCA2 gene was not expressed both in control cultures and in treated cells. Part B: mRNA levels of mismatch repair (MMR) and nucleotide excision repair genes (NER). PRKDC gene was not expressed both in control cultures and in treated cells. SAHA $24 \mathrm{~h}$, SAHA $48 \mathrm{~h}$, and SAHA $72 \mathrm{~h}$ are MSC cultures incubated with SAHA for 24,48 , and $72 \mathrm{~h}$, respectively. MS$27524 \mathrm{~h}, \mathrm{MS}-27548 \mathrm{~h}$, and MS-275 $72 \mathrm{~h}$ are MSC cultures incubated with MS-275 for 24, 48, and $72 \mathrm{~h}$, respectively. Further data on the role of these genes in DNA repair and RT-PCR parameters are in Table I. 
Italia). The percentage of 8oxodG-positive cells was calculated by counting at least 500 cells in different microscope fields.

\section{DNA extraction and T4 endonuclease $\mathrm{V}$ digestion}

Total DNA was extracted from MSC cultures following the classical phenol DNA extraction protocol (Sambrook and Russell, 200I). DNA $(2 \mu \mathrm{g})$ was digested for $\mathrm{I}-2 \mathrm{~h}$ at $37^{\circ} \mathrm{C}$ with T4 endonuclease V (Epicentre Biotechnologies, Madison, WI) and resolved by electrophoresis on a I\% agarose gel.

\section{Statistical analysis}

Statistical significance was evaluated by ANOVA analysis followed by a Student's $t$-test and Bonferroni's test.

\section{Results}

\section{Genes involved in DNA repair}

It is well known that HDACis trigger both DNA damage responses and actual DNA damage in cancer cells.

Based on this assumption, we investigated whether $\mathrm{HDACi}$ treatment of MSCs was accompanied by changes in expression of genes involved in different types of DNA repair. We selected a variety of genes involved in regulation of base and nucleotide excision repair (BER and NER, respectively), mismatch repair (MER) and double strand break repair (DSBR) (Hoeijmakers, 200I; Khanna and Jackson, 200I; Ronen and Glickman, 200I) (Table I). A complex expression pattern was observed following incubation with SAHA or MS-275 (Fig. IA,B). Nevertheless, interesting trends were identified.

Of interest in the MMR and NER groups, some genes showed a significant increase $(P<0.05)$ in the expression $24-48 \mathrm{~h}$ postincubation with HDAC inhibitors (Fig. I). Later on, their mRNA levels declined (Fig. IA,B). The temporary increased expression of some genes involved in DNA repair may be due to cell activity to neutralize damaging effect of HDACis. However, mesenchymal stem cells failed to properly repair DNA, thus inducing cell death phenomena and/or senescence as reported previously (Di Bernardo et al., 2009). This hypothesis is in agreement with Gaymes et al. (2006) that demonstrated how HDACis trigger in hematopoietic cells, not only widespread histone acetylation and DNA damage responses, but also actual DNA damage.

That a majority of the analyzed genes displayed significant expression changes upon incubation with SAHA or MS-275 suggested that regulation of their expression is greatly affected by HDACis. The complex expression pattern, with some genes upregulated and other underexpressed, did not allow to foresee if these changes allow cells to cope with stressful DNA damaging stimuli.

To gain insights on this issue, we evaluated the biological outcomes following treatment of MSCs with DNA damaging agents $\left(\mathrm{H}_{2} \mathrm{O}_{2}\right.$ and $\left.\mathrm{UV}\right)$ in presence of HDACls.

We treated MSCs with two different DNA-damaging agents, $\mathrm{H}_{2} \mathrm{O}_{2}$ and $U V$ radiation, in the presence of HDACis.

Initially, we analyzed the effects of these agents on MSCs by checking the percentage of senescent and apoptotic cells.

Under these settings, MSCs treated with $\mathrm{H}_{2} \mathrm{O}_{2}$ or UV radiation underwent apoptosis and senescence (Fig. 2). Incubation of MSC cells with SAHA exacerbated cell death phenomena, whereas only MS-275 caused a significant increase in the number of senescent cells treated with $\mathrm{H}_{2} \mathrm{O}_{2}$ or UV radiation (Fig. 2). The annexin $\mathrm{V}$ assay revealed a reduction in the number of early apoptotic cells in cultures incubated with DNA-damaging agents in the presence of both HDACis. We argued that the two drugs, when administered in the presence of $\mathrm{H}_{2} \mathrm{O}_{2}$ or UV radiation, might induce DNA damage, thus impairing the ability of the cells to trigger an "active defense mechanism" such as apoptosis. Notably, trypan blue staining revealed massive necrosis, which is considered a passive phenomenon associated with the failure of cell physiology (Fig. 2).

$\mathrm{H}_{2} \mathrm{O}_{2}$ produces multiple modifications in DNA. Oxidative attack by $\mathrm{OH}$ radicals on the deoxyribose moiety leads to the release of free bases from DNA, generating strand breaks with various sugar modifications and simple abasic (AP) sites. $\mathrm{H}_{2} \mathrm{O}_{2}$ also induces the modification of bases, such as formation of 8oxo-7,8-dihydroguanine (8oxodG). We analyzed the effects of hydrogen peroxide on the MSC by determining the percentage of oxo8dG-positive cells. Immunocytochemistry analysis showed that the percentage of oxo8dG-MSCs was significantly higher $(P<0.05)$ in samples incubated with either SAHA or MS275 compared with controls (Fig. 3).

UV radiation induces crosslinking between adjacent thymine bases, creating pyrimidine dimers. As such, the outcome of UV treatment was investigated by digesting genomic DNA with T4 endonuclease $\mathrm{V}$ in order to exame the level of pyrimidine dimers. This enzyme locates and binds to pyrimidine dimers in DNA, then cleaves the $\mathrm{N}$-glycosylic bond of the $5^{\prime}$ pyrimidine portion of the dimer and breaks the $3^{\prime}$ phosphodiester bond to

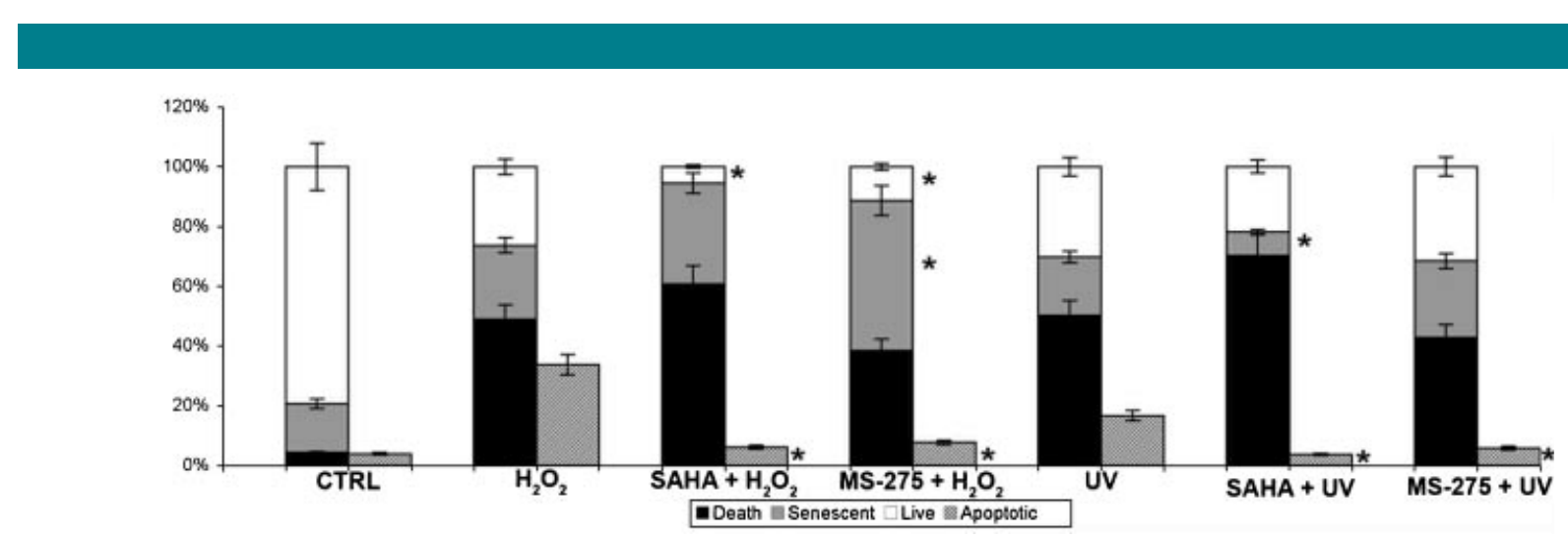

Fig. 2. Analysis of biological outcomes following treatment of MSCs with DNA-damaging agents in the presence of HDACis. For each treatment, the histogram shows the percentage of senescent and dead cells (apoptosis or necrosis). For each treatment, the percentage of apoptotic cells is indicated in the side column. CTRL are control MSC cultures. $\mathrm{H}_{2} \mathrm{O}_{2}$ and $\mathrm{UV}$ are $M S C$ cultures that were treated with either $+\mathrm{H}_{2} \mathrm{O}_{2}$ or UV radiation. SAHA $+\mathrm{H}_{2} \mathrm{O}_{2}$ and SAHA + UV are MSC cultures treated with DNA damaging agents in presence of SAHA. MS-275 + $\mathrm{H}_{2} \mathrm{O}_{2}$ and $\mathrm{MS}-275+\mathrm{UV}$ are MSC cultures treated with DNA damaging agents in presence of MS-275. Statistical analysis was carried out comparing SAHA + $\mathrm{H}_{2} \mathrm{O}_{2}$ and $\mathrm{MS}$ $275+\mathrm{H}_{2} \mathrm{O}_{2}$ with $\mathrm{H}_{2} \mathrm{O}_{2}$ (MSC cultures that were treated with $\mathrm{H}_{2} \mathrm{O}_{2}$ ). Same analysis was performed on SAHA + UV and MS-275 + UV with UV (MSC cultures that were treated with UV radiation) (data are expressed $\pm S E, n=3 ;{ }^{*} P<0.05$ ). 

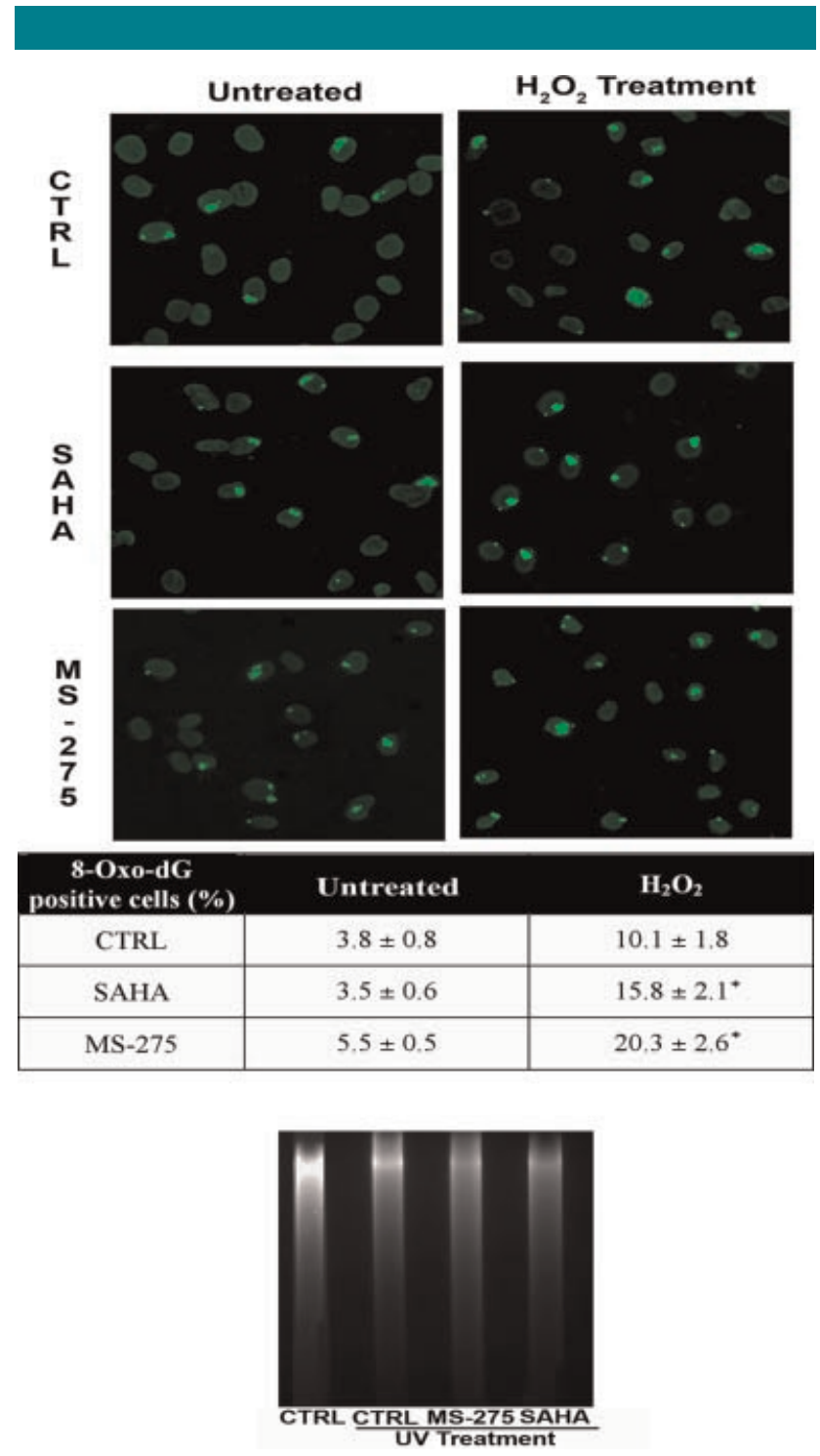

Fig. 3. Analysis of DNA damage. Top: Fluorescence photomicrographs display cells stained with anti-8-oxo-dG (green). A representative microscopic field for each treatment is shown. Mean incidence values of 8-oxo-dG are indicated in the corresponding table ( $\pm \mathrm{SE}, \mathrm{n}=3$; $\left.{ }^{*} \mathrm{P}<0.05\right)$. " $\mathrm{H}_{2} \mathrm{O}_{2}$ treatment" and "Untreated" and columns refers to MSC that were either incubated or not hydrogen peroxide, respectively. SAHA and MS-275 indicates MSC cultures treated with SAHA or MS-275, respectively. Bottom: agarose gel electrophoresis of genomic DNA digested with T4 endonuclease V. CTRL are control MSC cultures. CTRL-, MS-275- and SAHA-UV treatment indicates UV irradiated cells either in presence or absence of HDACis.

the resulting abasic site. This induces fragmentation of DNA-containing dimers that can be easily analyzed. UV radiation induced degradation of DNA in MSC cultures. Interestingly, treatment of cells with HDACis did not augment the fragmentation of DNA, as detected by agarose gel electrophoresis (Fig. 3).

\section{Molecular analysis of HDACis treatment}

Once we analyzed the biological consequences of HDACis in MSCs, we attempted to elucidate the molecular pathways involved in HDACi-induced phenomena. Initially, we analyzed the expression of retinoblastoma gene family members $(R B$,
$P / 07$, and RB2/PI30) as well as expression of P53, which is known to control cell cycle arrest, differentiation, apoptosis, and/or senescence processes (Giacca and Kastan, 1998; Galderisi et al., 2006; Campisi and d'Adda di Fagagna, 2007; Oberdoerffer and Sinclair, 2007).

$\mathrm{H}_{2} \mathrm{O}_{2}$ induced upregulation of $\mathrm{RB}$ with a concomitant decrease in RB2/PI30 and PI07 protein levels (Fig. 4 and Supplementary Fig. I). P53 protein was strongly activated, as indicated by upregulation of the acetylated (K382) P53 (Fig. 4 and Supplementary Fig. I) (Sakaguchi et al., 1998). RB appears to be involved in the rescue from apoptosis, whereas P53 can activate programmed cell death pathways (Galderisi et al., 2003, 2006). Thus, it is reasonable to hypothesize that apoptotic pathways overcome survival mechanisms in cells treated with hydrogen peroxide. UV radiation did not significantly affect expression of the RB family of genes. Nevertheless, we did detect activation of P53 (Fig. 4 and Supplementary Fig. I).

Retinoblastoma proteins and P53 cooperate with cyclin kinase inhibitors (CKIs) to regulate cell cycle progression, senescence, and apoptosis (Galderisi et al., 2003). We also examined expression of some CKI genes following incubation of MSC cultures with DNA-damaging agents.

Both $\mathrm{H}_{2} \mathrm{O}_{2}$ and $U V$ radiation induced a significant increase in the expression of $\mathrm{PI} 6^{\mathrm{INK} 4 \mathrm{~A}}$ and $\mathrm{P} 2 \mathrm{I}^{\mathrm{CIPI}}$ (Fig. 4 and Supplementary Fig. I). P27 ${ }^{\mathrm{KIPI}}$ was downregulated following treatment with both damaging agents (Fig. 4 and Supplementary Fig. I).

We also analyzed the expression of cyclins following DNA damage. UV treatment induced significant upregulation of cyclin $\mathrm{DI}$ and cyclin $\mathrm{E}$ along with a decrease in cyclin A. Cyclin E was also increased by $\mathrm{H}_{2} \mathrm{O}_{2}$ treatment together with a significant downregulation of cyclin D (Fig. 4 and Supplementary Fig. I).

Our results are in agreement with other reports showing that $\mathrm{H}_{2} \mathrm{O}_{2}$ and $U V$ radiation induce $G_{1}$ and/or $S / G_{2}$ cell cycle arrest, respectively (Lutzen et al., 2004; Upadhyay et al., 2007; Lee et al., 2008; Stubbert et al., 2009). Indeed, flow cytometry analysis showed that $\mathrm{H}_{2} \mathrm{O}_{2}$ treatment induced a significant reduction of S-Phase MSCs (13.9\% vs. 8.1\%) along with accumulation of $G_{1}$ cells (Fig. 5). By contrast, in UV treated MSCs the reduction in S-phase cells is associated both with an increase of $G_{1}$ and $S / G_{2}$ cells (Fig. 5).

Overall, these data are consistent with an induction of apoptosis/necrosis via RB/P53/P2I/PI6 pathways in $\mathrm{H}_{2} \mathrm{O}_{2}$-treated MSCs. On the other hand, impairment of MSC physiology by UV radiation appears to rely mainly on P53/PI6/ P2I (Fig. 4 and Supplementary Fig. I).

HDACi treatments boosted death phenomena induced by DNA-damaging agents, partially through pathways that have previously been identified. In fact, only P53 and PI $6^{\text {INK4A }}$ were upregulated in MSCs treated with hydrogen peroxide in the presence of SAHA (Fig. 4 and Supplementary Fig. I). Following incubation with MS-275 and $\mathrm{H}_{2} \mathrm{O}_{2} \mathrm{PI} 6^{\mathrm{INK} 4 \mathrm{~A}}$ and acetylated P53 were upregulated compared with controls (Fig. 4 and Supplementary Fig. I). These results are in good agreement with the observation that both SAHA and MS-275 induced death phenomena, whereas MS-275 seemed to also trigger cellular senescence.

In UV-irradiated MSCs we observed an increased expression of P2 ${ }^{\mathrm{CIPI}}$ and acetylated P53 compared with untreated cells (Fig. 4 and Supplementary Fig. I). The increased expression of these proteins still persisted in presence of either SAHA or MS-275 (Fig. 4 and Supplementary Fig. I). In UV irradiated cells, in presence of SAHA or MS-275, we detected an increase the expression of $\mathrm{P} 16^{\text {INK4A }}$ compared with UV-irradiated only (Fig. 4 and Supplementary Fig. I). In the presence of HDACis, UV treatment did not significantly affect the expression of RB and RB2 genes (Fig. 4 and Supplementary Fig. I). Both drugs induced a significant decrease in P27 as compared with healthy controls (Fig. 4 and Supplementary Fig. I). 


\section{$\mathrm{H}_{2} \mathrm{O}_{2}$}
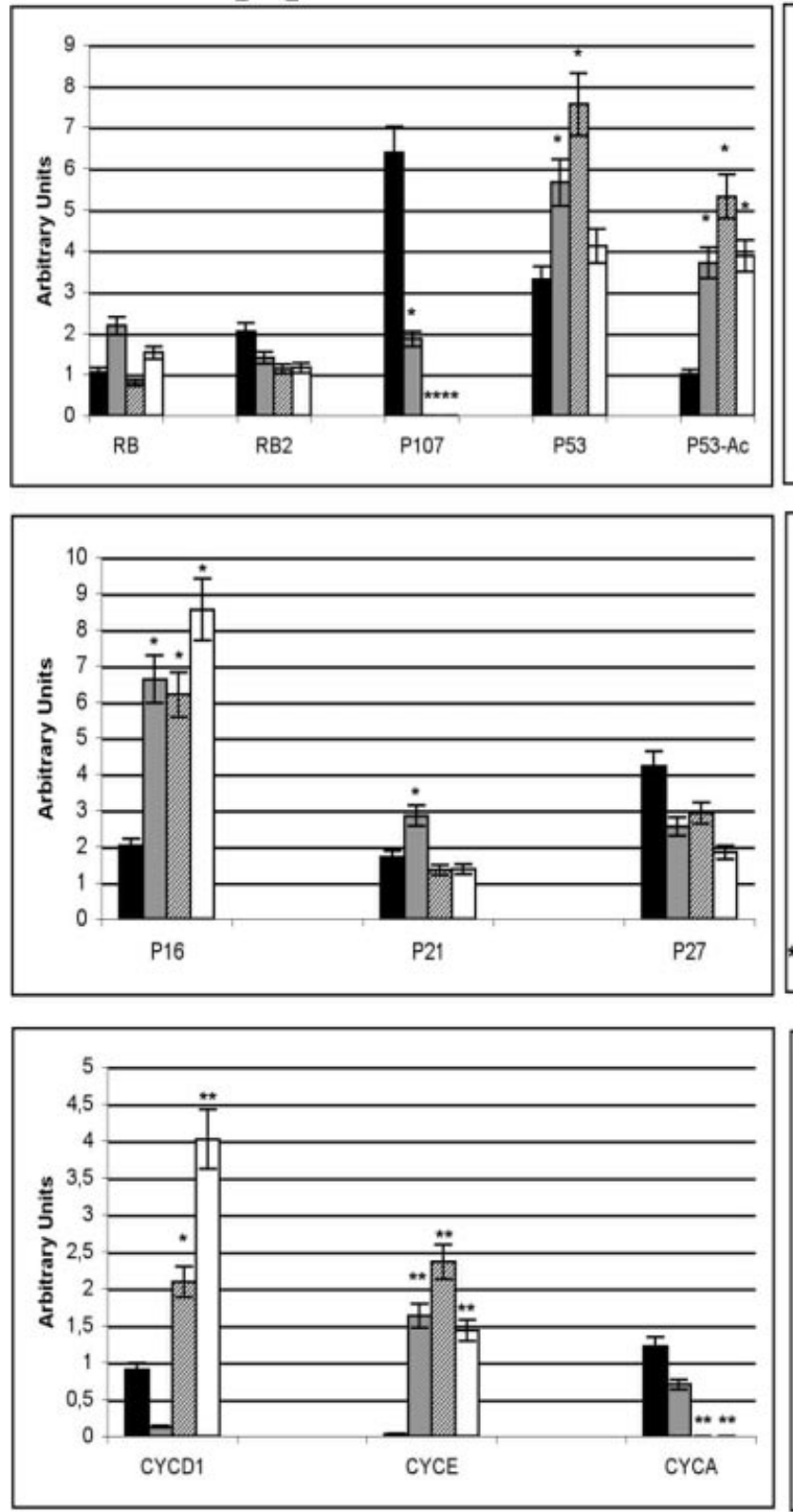

CTRL $\square C T R L+\mathrm{H}_{2} \mathrm{O}_{2} \cong \mathrm{SAHA}+\mathrm{H}_{2} \mathrm{O}_{2} \square \mathrm{MS}-275+\mathrm{H}_{2} \mathrm{O}_{2}$

\section{UV}
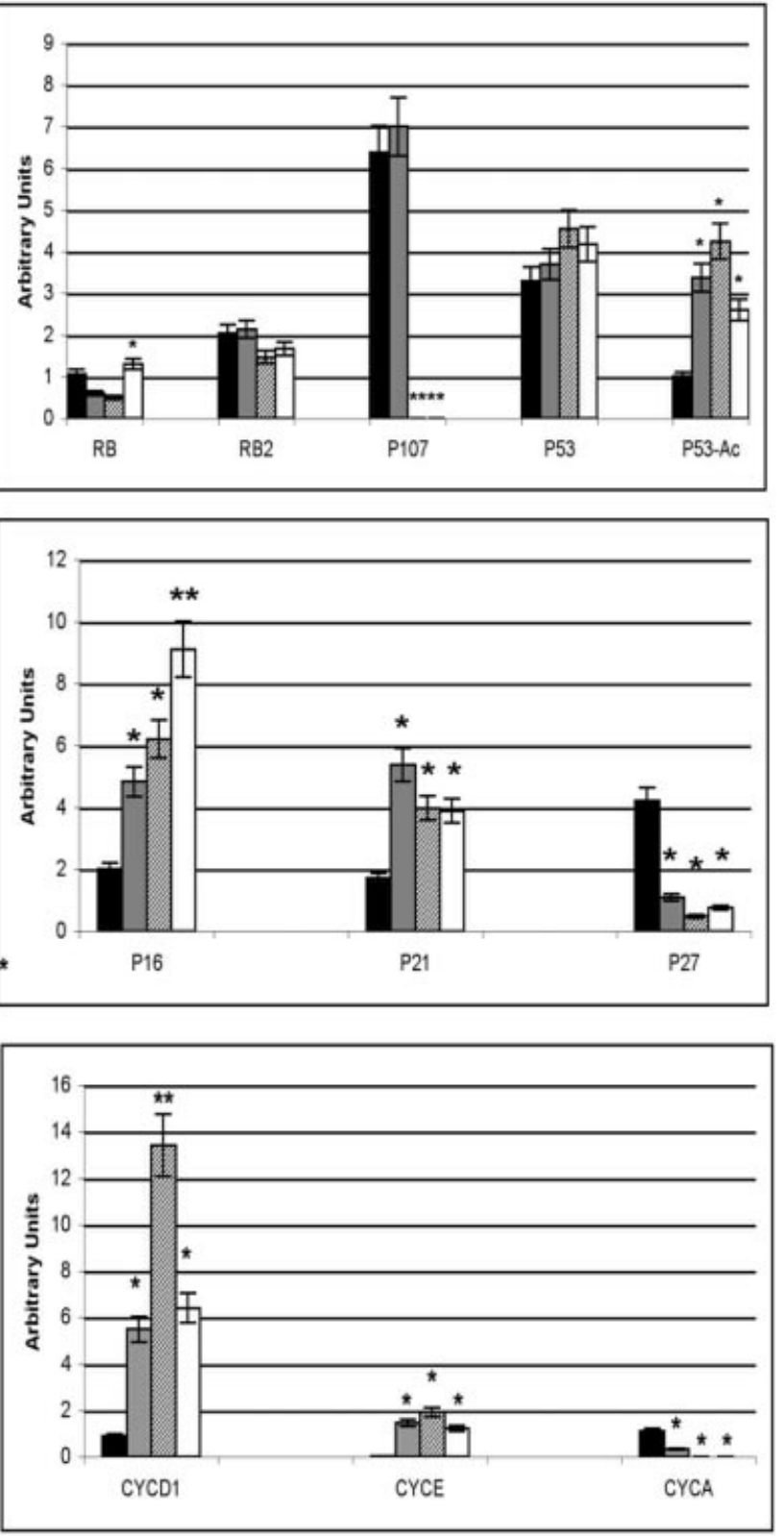

- CTRL $\square C T R L+U V \mathbb{Z} S A H A+U V \square M S+U V$

Fig. 4. Western blot analysis in MSCs treated with DNA-damaging agents $\left(\mathrm{H}_{2} \mathrm{O}_{2}\right.$ and UV radiation) DNA-damaging agents either in the presence and absence of HDACis. The protein levels were normalized with respect to GAPDH and alpha-tubulin, which were chosen as internal controls ( \pm SE, $n=3 ;{ }^{*} P<0.05 ;{ }^{*} P<0.01$ ). CTRL are control MSC cultures. CTRL $+\mathrm{H}_{2} \mathrm{O}_{2}$ and CTRL $+\mathrm{UV}$ are MSC cultures that were treated with either $+\mathrm{H}_{2} \mathrm{O}_{2}$ or UV radiation. SAHA $+\mathrm{H}_{2} \mathrm{O}_{2}$ and SAHA $+\mathrm{UV}$ are MSC cultures treated with DNA damaging agents in presence of SAHA. $\mathrm{MS}+\mathrm{H}_{2} \mathrm{O}_{2}$ and $\mathrm{MS}+\mathrm{UV}$ are MSC cultures treated with DNA damaging agents in presence of MS-275.

The expression patterns of cyclins in $\mathrm{H}_{2} \mathrm{O}_{2}$ - and UV-treated cells were not modified by SAHA and MS-275, but cyclin D significantly increased following treatment with $\mathrm{H}_{2} \mathrm{O}_{2}$ and HDACi as opposed to treatment with hydrogen peroxide alone (Fig. 4 and Supplementary Fig. I).

\section{Discussion}

HDAC inhibitors, such as SAHA and MS-275, are currently under investigation as potential cancer therapeutics. In order to enhance their efficacy and safety, the effects of these molecules on normal cells should be better elucidated (Dokmanovic and Marks, 2005; Rodriquez et al., 2006).

The mechanism(s) behind the pleiotropic cellular effects of HDACis are still unclear. For example, HDACi-induced antitumor effects have been attributed to the transcriptional activation of particular target genes, such as P2IWAFI/CIPI, TRAIL, and FAS (Kim et al., 2003; Bots and Johnstone, 2009). The mitochondrial death pathway, and in particular BMF, has been implicated in the action of HDACi (Kim et al., 2003; Bots 

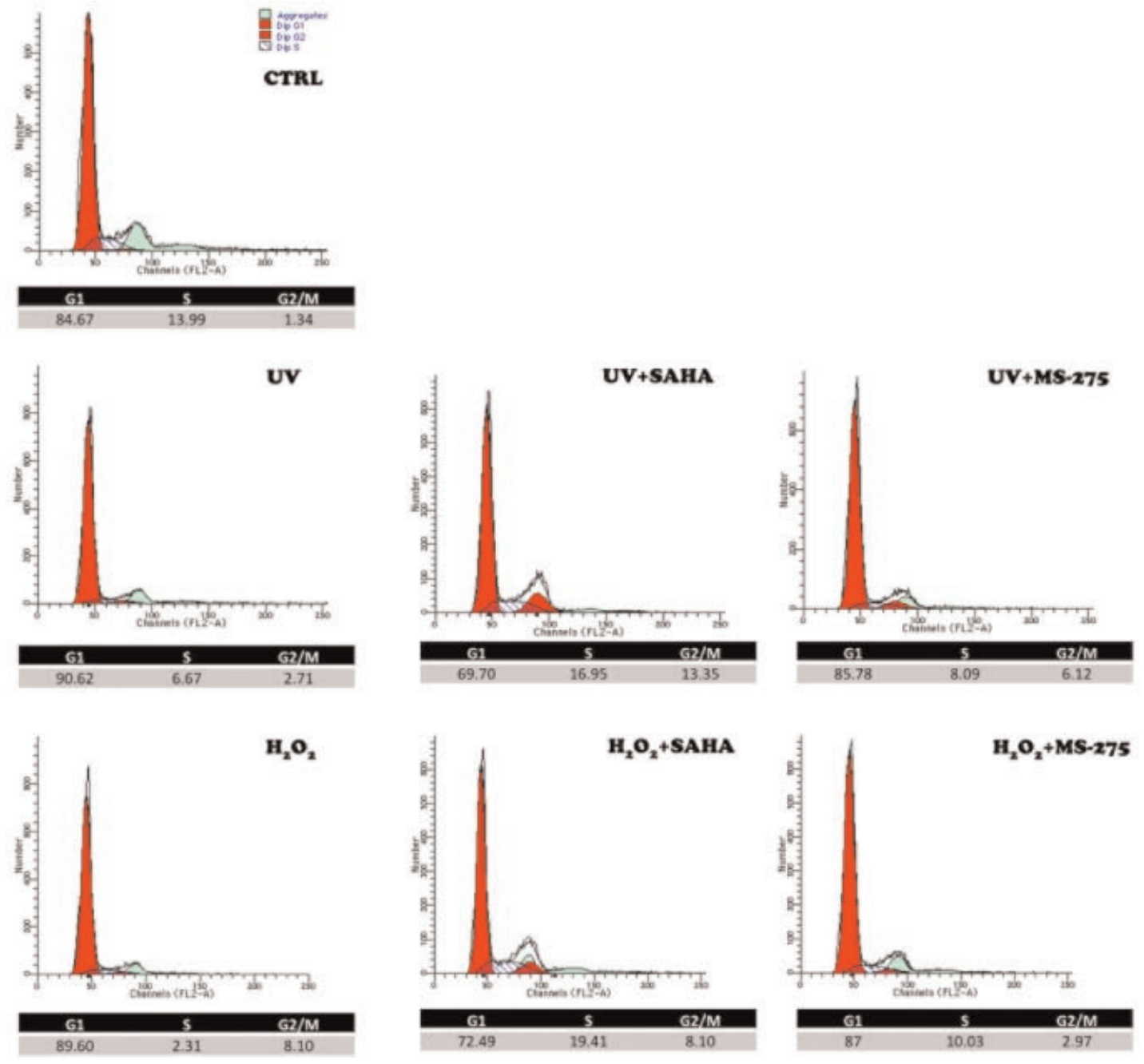

Fig. 5. A representative FACS analysis of MSCs, treated with DNA-damaging agents $\left(\mathrm{H}_{2} \mathrm{O}_{2}\right.$ and $U \mathrm{~V}$ radiation) either in the presence and absence of HDACis. CTRL are control MSC cultures. $\mathrm{H}_{2} \mathrm{O}_{2}$ and UV are MSC cultures that were treated with either $+\mathrm{H}_{2} \mathrm{O}_{2}$ or $\mathrm{UV}$ radiation. $\mathrm{H}_{2} \mathrm{O}_{2}+\mathrm{SAHA}$ and UV + SAHA are MSC cultures treated with DNA damaging agents in presence of SAHA. $\mathrm{H}_{2} \mathrm{O}_{2}+$ MS-275 and UV + MS-275 are MSC cultures treated with DNA damaging agents in presence of MS-275. [Color figure can be viewed in the online issue, which is available at wileyonlinelibrary.com.]

and Johnstone, 2009). In our previous report on the effects of HDACis on MSCs, we observed a significant upregulation of $\mathrm{P} 27 / \mathrm{KIPI}$ and PI6/INK4A mRNA levels, suggesting that gene transcription can be modulated by HDACis in these cell types (Di Bernardo et al., 2009). In the present study, we observed that, following HDACi treatment, MSCs were more sensitive to DNA damage. This phenomenon could be a direct consequence of regulation of genes involved in DNA repair. Nevertheless, in addition to the transcriptional model just discussed, acetylation of other non-histone proteins also appears to be important for $\mathrm{HDACi}$ activity. This pathway could also be involved in the impairment of DNA damage repair in MSCs following $\mathrm{HDACi}$ treatment.

Whatever the mechanisms involved, our research suggests that these phenomena have to be carefully analyzed. SAHA and MS-275, even at low effective doses, can impair the biology of MSCs, decreasing their ability to survive exposure to DNA-damaging agents.

In fact, as expected, MSCs treated with $\mathrm{H}_{2} \mathrm{O}_{2}$ and UV radiation underwent apoptosis and/or senescence (Sethe et al., 2006; Campisi and d'Adda di Fagagna, 2007; Sharpless and
DePinho, 2007; Galderisi et al., 2009) (Fig. 2). Interestingly, treatment of cells with HDACis greatly impaired cell physiology, triggering necrotic phenomena (Fig. 2). This may be the outcome of severe alterations to DNA, as suggested by the 8oxodG assay (Fig. 3).

In MSC cultures, RB/P53/P2I/PI 6 pathways appeared to be associated with induction of apoptosis/necrosis through $\mathrm{H}_{2} \mathrm{O}_{2}$ treatment. In contrast, cell death induced by UV radiation appears to rely mainly on P53/PI6/P2I (Fig. 4). Interestingly, HDACi treatments further augmented death phenomena induced by DNA-damaging agents. This seemed to occur partially through previously identified pathways (Fig. 4).

\section{Conclusions}

Overall, our data suggest that HDACis may render cells very sensitive to environmental stress. This is a key issue, since in several therapeutic protocols, treatment of cancer patients relies upon the combined action of HDACis and a series of conventional DNA-damaging chemotherapeutic drugs (ellipticine, a DNA intercalator; doxorubicin, a DNA groove 
binder and intercalator; cisplatin, a DNA cross-linking agent) (Karagiannis and El-Osta, 2006).

These regimens may greatly affect the functionality of stem cell reservoirs, including the mesenchymal stem cell niche. For this reason, further safety precautions are necessary to prevent side effects following therapeutic use of SAHA and MS-275.

\section{Acknowledgments}

This work was partially supported by Sbarro Health Research Organization funds to U.G. and EU-FP7 ATLAS project no. 221952 ; “Associazione Italiana per la Ricerca sul Cancro" funds were received by L.A. We thank Maria Rosaria Cipollaro for technical assistance.

\section{Literature Cited}

Beyer Nardi N, da Silva Meirelles L. 2006. Mesenchymal stem cells: Isolation, in vitro expansion and characterization. Handbook Exp Pharmacol 249-282.

Bots M. Johnstone RW. 2009. Rational combinations using HDAC inhibitors. Clin Cancer Res 15:3970-3977.

Campisi J, d'Adda di Fagagna F. 2007. Cellular senescence: When bad things happen to good cells. Nat Rev Mol Cell Biol 8:729-740.

Di Bernardo G, Squillaro T, Dell'Aversana C, Miceli M, Cipollaro M, Cascino A, Altucci L, Galderisi U. 2009. Histone deacetylase inhibitors promote apoptosis and senescence in human mesenchymal stem cells. Stem Cells Dev 18:573-581.

Dokmanovic M, Marks PA. 2005. Prospects: Histone deacetylase inhibitors. J Cell Biochem 96:293-304.

Dominici M, Le Blanc K, Mueller I, Slaper-Cortenbach I, Marini F, Krause D, Deans R, Keating A, Prockop D, Horwitz E. 2006. Minimal criteria for defining multipotent mesenchymal stromal cells. The International Society for Cellular Therapy position statement. Cytotherapy 8:315-317.

Duvic M, Vu J. 2007. Vorinostat: A new oral histone deacetylase inhibitor approved for cutaneous T-cell lymphoma. Expert Opin Investig Drugs 16: I I I-1 I20.

Duvic M, Talpur R, Ni X, Zhang C, Hazarika P, Kelly C, Chiao JH, Reilly JF, Ricker JL, Richon VM, Frankel SR. 2007. Phase 2 trial of oral vorinostat (suberoylanilide hydroxamic acid, SAHA) for refractory cutaneous T-cell lymphoma (CTCL). Blood 109:31-39.

Galderisi U, Di Bernardo G, Cipollaro M, Peluso G, Cascino A, Cotrufo R, Melone MA. 1999 Differentiation and apoptosis of neuroblastoma cells: Role of $\mathrm{N}$-myc gene product. J Cell Biochem 73:97-105.

Galderisi U, Jori FP, Giordano A. 2003. Cell cycle regulation and neural differentiation. Oncogene 22:5208-5219.

Galderisi U, Cipollaro M, Giordano A. 2006. The retinoblastoma gene is involved in multiple aspects of stem cell biology. Oncogene 25:5250-5256.

Galderisi U, Helmbold H, Squillaro T, Alessio N, Komm N, Khadang B, Cipollaro M, Bohn W, Giordano A. 2009. In vitro senescence of rat mesenchymal stem cells is accompanied by downregulation of stemness-related and DNA damage repair genes. Stem Cells Dev V 18:1033-1042.

Gaymes T], Padua RA, Pla M, Orr S, Omidvar N, Chomienne C, Mufti G], Rassool FV. 2006. Histone deacetylase inhibitors (HDI) cause DNA damage in leukemia cells: A mechanism for leukemia-specific HDI-dependent apoptosis? Mol Cancer Res 4:563-573.

Giacca A, Kastan M. 1998. The complexity of p53 modulation: Emerging patterns from divergent signals. Genes Dev 12:2773-2783.
Heltweg B, Dequiedt F, Marshall BL, Brauch C, Yoshida M, Nishino N, Verdin E, Jung M. 2004. Subtype selective substrates for histone deacetylases. J Med Chem 47:52355243.

Hoeijmakers JH. 200I. Genome maintenance mechanisms for preventing cancer. Nature 4II:366-374.

Karagiannis TC, El-Osta A. 2006. Clinical potential of histone deacetylase inhibitors as stand alone therapeutics and in combination with other chemotherapeutics or radiotherapy for cancer. Epigenetics 1:|12|-126.

Khanna KK, Jackson SP. 200I. DNA double-strand breaks: Signaling, repair and the cancer connection. Nat Genet 27:247-254.

Kim DH, Kim M, Kwon HJ. 2003. Histone deacetylase in carcinogenesis and its inhibitors as anti-cancer agents. J Biochem Mol Biol 36:110-119.

Kummar S, Gutierrez M, Gardner ER, Donovan E, Hwang K, Chung EJ, Lee MJ, Maynard K Kalnitskiy M, Chen A, Melillo G, Ryan QC, Conley B, Figg WD, Trepel JB, Zwiebel J, Doroshow JH, Murgo AJ. 2007. Phase I trial of MS-275, a histone deacetylase inhibitor, administered weekly in refractory solid tumors and lymphoid malignancies. Clin Cance Res 13:54II-54I7.

Lee SH, Heo JS, Lee MY, Han HJ. 2008. Effect of dihydrotestosterone on hydrogen peroxide-induced apoptosis of mouse embryonic stem cells. J Cell Physiol 216:269_ 275

Lutzen A, Bisgaard HC, Rasmussen LJ. 2004. Cyclin DI expression and cell cycle response in DNA mismatch repair-deficient cells upon methylation and UV-C damage. Exp Cell Res 292:123-134.

Muller-Sieburg CE, Deryugina E. 1995. The stromal cells' guide to the stem cell universe. Stem Cells 13:477-486.

Oberdoerffer P, Sinclair DA. 2007. The role of nuclear architecture in genomic instability and ageing. Nat Rev Mol Cell Biol 8:692-702.

Prockop DJ. 1997. Marrow stromal cells as stem cells for nonhematopoietic tissues. Science 276:71-74.

Ramalingam SS, Parise RA, Ramananthan RK, Lagattuta TF, Musguire LA, Stoller RG, Potter DM, Argiris AE, Zwiebel JA, Egorin MJ, Belani CP. 2007. Phase I and pharmacokinetic study of vorinostat, a histone deacetylase inhibitor, in combination with carboplatin and paclitaxel for advanced solid malignancies. Clin Cancer Res 13:36053610

Rodriquez M, Aquino M, Bruno I, De Martino G, Taddei M, Gomez-Paloma L. 2006 Chemistry and biology of chromatin remodeling agents: State of art and future perspectives of HDAC inhibitors. Curr Med Chem 13:1119-1 I39.

Ronen A, Glickman BW. 200I. Human DNA repair genes. Environ Mol Mutagen 37:24I-283. Sakaguchi K, Herrera JE, Saito S, Miki T, Bustin M, Vassilev A, Anderson CW, Appella E. 1998 DNA damage activates $p 53$ through a phosphorylation-acetylation cascade. Genes Dey |2:283|-284|.

Sambrook J, Russell DW. 200I. Molecular cloning: A laboratory manual. Cold Spring Harbor, NY: CSHL Press.

Santos-Rosa H, Caldas C. 2005. Chromatin modifier enzymes, the histone code and cancer Eur J Cancer 4I:238I-2402.

Sethe S, Scutt A, Stolzing A. 2006. Aging of mesenchymal stem cells. Ageing Res Rev 5:91-116. Sharpless NE, DePinho RA. 2007. How stem cells age and why this makes us grow old. Nat Rev Mol Cell Biol 8:703-7।3.

Stubbert LJ, Spronck JC, Hamill JD, McKay BC. 2009. Ultraviolet light induces the sustained unscheduled expression of cyclin $E$ in the absence of functional p53. Cell Cycle 8:29953002 .

Ungerstedt JS, Sowa Y, Xu WS, Shao Y, Dokmanovic M, Perez G, Ngo L, Holmgren A, Jiang X, Marks PA. 2005. Role of thioredoxin in the response of normal and transformed cells to histone deacetylase inhibitors. Proc Natl Acad Sci USA 102:673-678.

Upadhyay D, Chang W, Wei K, Gao M, Rosen GD. 2007. Fibroblast growth factor-10 prevents $\mathrm{H} 2 \mathrm{O} 2$-induced cell cycle arrest by regulation of $\mathrm{GI}$ cyclins and cyclin dependent kinases. FEBS Lett 58I:248-252.

Zhang J, Niu C, Ye L, Huang H, He X, Tong WG, Ross J, Haug J, Johnson T, Feng JQ, Harris S, Wiedemann LM, Mishina Y, Li L. 2003. Identification of the haematopoietic stem cell niche and control of the niche size. Nature 425:836-84I. 